\title{
Impact of Electronic Commerce Technology for Students
}

\author{
A Nursikuwagus ${ }^{1}$, C T H Sagala ${ }^{2}$ \\ \{agusnursikuwagus@email.unikom.ac.id $^{1}$, cthsagala@email.unikom.ac.id $^{2}$ \} \\ Department of Information Systems Universitas Komputer Indonesia, Bandung, \\ Indonesia ${ }^{1}$, Faculty of Engineering and Computer Science, Universitas Komputer \\ Indonesia, Bandung, Indonesia ${ }^{2}$
}

\begin{abstract}
The purpose of this research is to find out how the impact of e-commerce for students in entrepreneurship and what benefits e-commerce provides to students. In this study used a descriptive method, which is used to present an overview of events or phenomena that are taking place at the present or in the past. The results of this study are to find out how far and how much influence e-commerce has on students. This research was conducted by discussing how the system of sales, payment, and order transactions can be done by students using e-commerce technology. Easiness of transaction was provided by e-commerce with the e-payment, the consumer can buy without physical money. In the cloud era and IoT, every purchasing product, we only browsing and obtain the interested product and then pay. Some e-commerce has provided for registry form. It used for the consumer who has not account member on their transaction. Reduce the time, speed, and doing everywhere are to be jargon on the e-commerce concepts. The result that IoT can bring an influence to the student. The digital era brings the student more accessible to buy something on the internet. Service like purchase order, payment, and claim have provided by the company to make consumer convenience and guarantee. The impact of this research is that a student can increase the knowledge about e-commerce, how to use, how to pay, and how to become a member.
\end{abstract}

Keyword : E-commerce, Business, Marketing

\section{Introduction}

E-commerce is a technology on the internet support that helps the user to distribute product and service. Many e-commerce on the internet which provided service and sell a product to fulfil the consumer needs. Now e-commerce is no longer only used by large companies but is also used by small businesses. By using e-commerce marketing, small business products can be spread widely so that all circles, especially students, can get higher profits.

E-commerce as the use of the Internet to conduct business transactions nationally or internationally, as represented by WTO [1]. The other scholar responded that because ecommerce continues to grow, its impact on work and wages will be the result of a series of complex interactive forces [2]. Besides that, online marketing defines an integral part of ecommerce today and encompasses various corporate ways such as e-mail marketing, content marketing, social media, affiliate marketing, and so on [3]. Increasing e-commerce in many areas caused traffic of transaction is growing up too [4]. Such transactions are not direct but mediated, placing the buyer in a weak position against the seller, especially in the case of a transaction failure [4]. Another definition of e-commerce is the purchase or sale of goods between businesses, households, individuals, government, and other organisations through computer networks with the internet [5]. E-commerce defines an electronic process where individuals or organisations conduct transactions, such as buying, selling, transferring, or exchanging products, services, and information [6]. The influencing of e-commerce can be seen that the adoption of e-commerce by SMEs in Indonesia is influenced by several factors that are considered benefits, technology readiness, owner innovation, the owner is IT experience and owner's IT capabilities [7]. On the global economy, many markets are becoming increasingly international and competitive [8]. Technological advances in logistics and distribution allow almost every business to buy, sell and work together on a global scale and even smaller, locally oriented businesses are forced to see themselves in a global context to survive in this challenging new business environment [8]. E-commerce is one of the methods used by Small and Medium Enterprises (SMEs) to market their products [9]. E- 
commerce is a store in front of a digital screen that is connected to the internet, which is designed to show visitors that you have something to sell online [10]. This is also reinforced by this statement [11].

Following the frequently research step, we used a method to complete the research and give the right path of research. The research method was a descriptive-analytic to review some e-commerce and give some comment about growing e-commerce. We used some steps such as survey, analysis, and conclusion. The results of this study are to study the extent and extent of e-commerce with students. This research was conducted by discussing how the process of sales transactions, payments, and bookings made by students using e-commerce technology. Impact of the study is that a student can increase the knowledge about e-commerce, and understand how to use, how to pay, and how to become a member.

\section{Material and Methods}

The research method used in this experiment is descriptive qualitative, which provides a comprehensive picture of a problem that develops with a creative idea that will be an innovative solution through an innovative policy. Descriptive qualitative is one statistical method that explains phenomena based on review and some knowledge as an induction method to reach some answer. The method is consisted of survey, analysis, and find the answer about phenomena. The survey is one action direct to consumer and provides some questioner to ask some critical questions about e-commerce and its use. The analysis is an activity to measure some questions and correlation within phenomena. Is there any significant answer that correlated within phenomena, we should to explain and give some reason why this occurred? The last step, to conclude the result from the descriptive-analytic and give some statement that related to the study.

\section{Results and Discussion}

To attract buyers to visit the store page or e-commerce site in the business world, ecommerce players can make the appearance of e-commerce webs as attractive as possible and make the appearance easy for users to understand. Because with ease and attractive appearance is one of the supporting factors for the success of e-commerce. For example, an e-commerce site that provides a place for sellers and buyers with e-commerce sites like this can support the rapid development of e-commerce business activities that provide many conveniences and also provide online and virtual payment services which will certainly facilitate business ecommerce that takes place [2].

Orders that can be made anywhere and anytime become the power of the users' interest in conducting e-commerce transaction activities [4]. The following are examples of user interest in making transactions because of the convenience provided in transactions on an online shop shown in Fig 1.

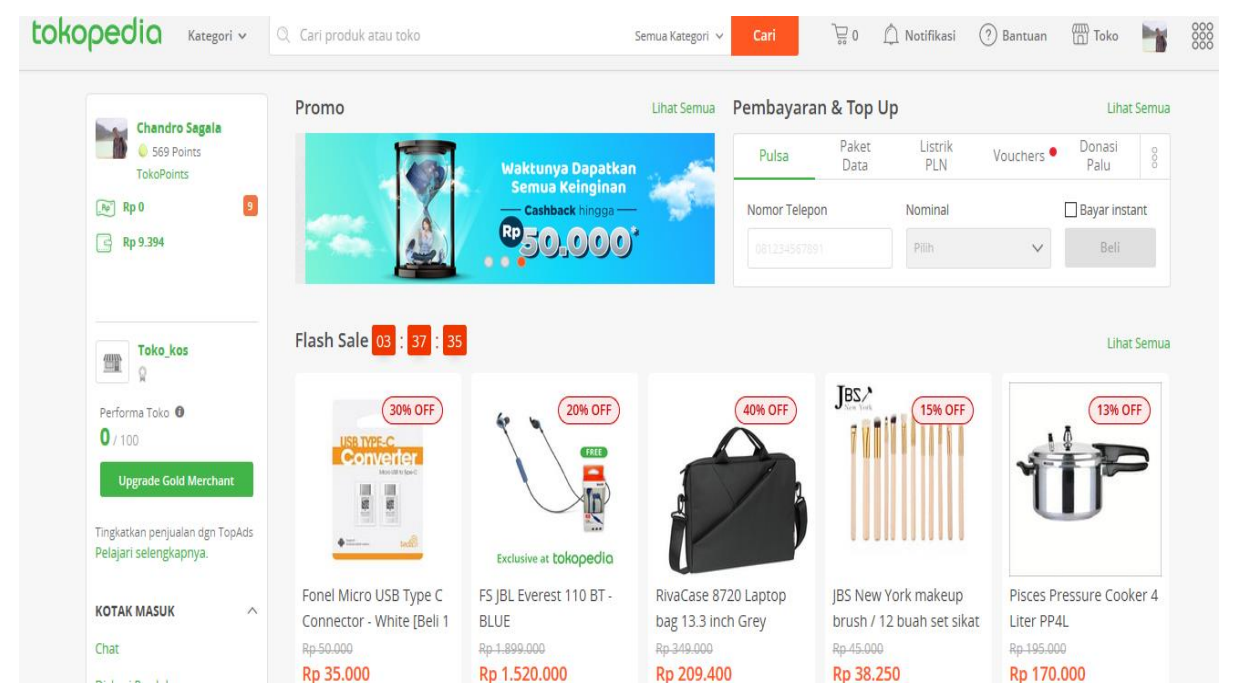

Fig 1. Main Menu. The figure was adopted from www.tokopedia.com was taken on Nov 24, 2018. 
To make it easy for sellers, the appearance of e-commerce sites is made as easy as possible to be used by business people (sellers). The shop's main view is made simple so that sellers can easily add products and prices from the products they sell. The following example is an attractive display on the main page of the store that the sellers use to add the products and services they provide shown in Fig 2.

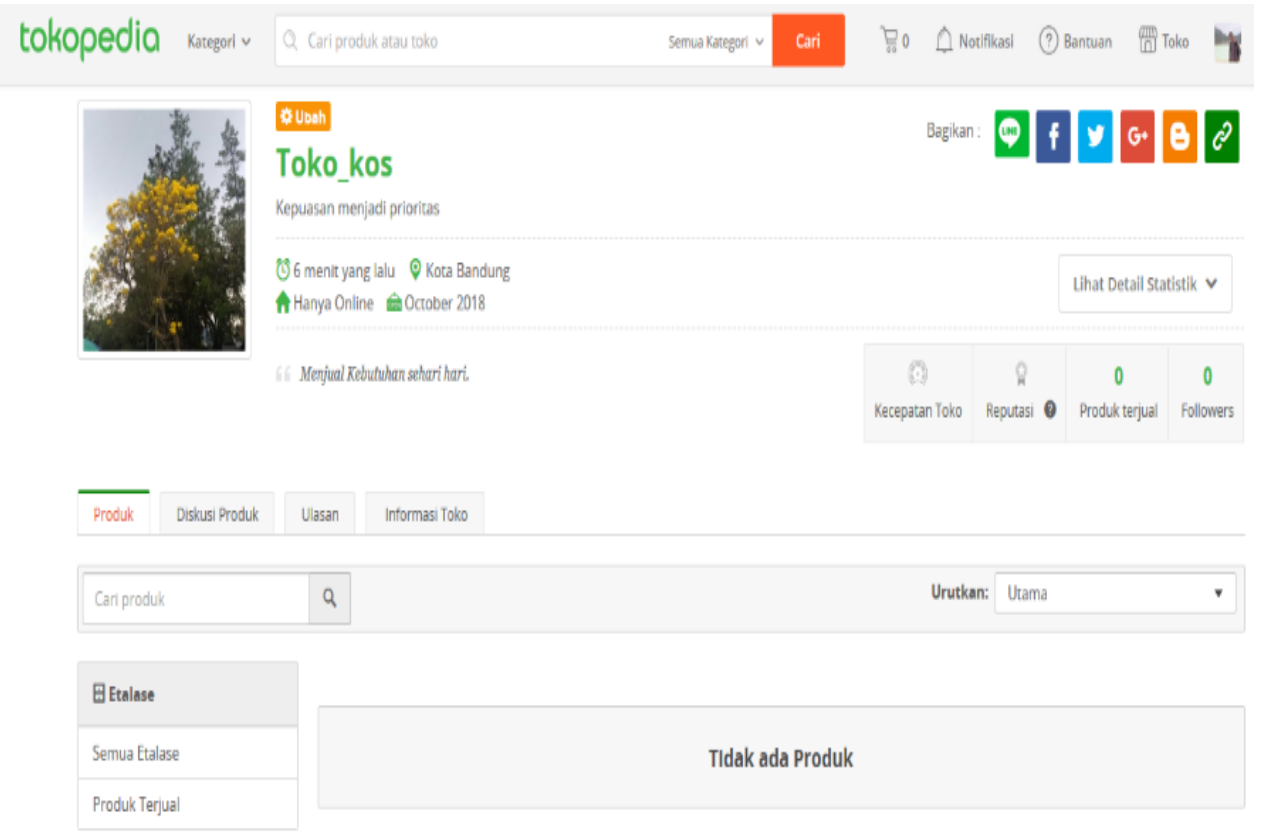

Fig 2. Main store page view. The figure was adopted from www.tokopedia.com was taken on Nov 24, 2018.

In the display of added goods, the seller can easily add the product to be sold. Products that can be sold are also not restricted, meaning that the seller can sell anything but still follow the rules of the applicable regulations such as not being allowed to sell narcotics or explosives. In this display, the seller can list the items, prices, and descriptive of the products they sell [7] so that the buyer can later see the product and buy the product sold by the seller. Examples of display pictures add products to the online shop store page in Fig 3.

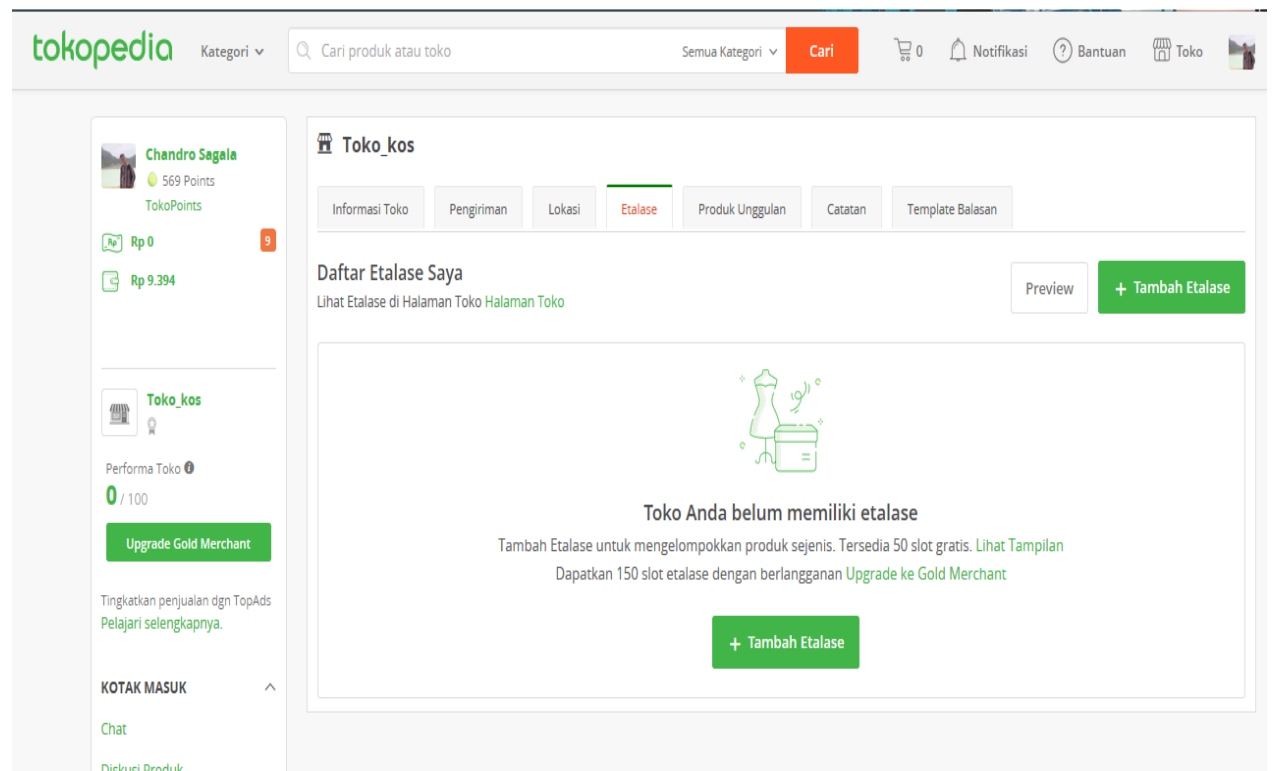

Fig 3. Add products. The figure was adopted from www.tokopedia.com was taken on Nov 24, 2018.

In the display of shipping options, sellers can change or edit the shipping options of the products they sell to buyers, with this shipping option online shop traders can easily choose 
what shipping courier services they want to use to help their business in the shipping field. By the delivery of goods delivery courier services in the area of the seller. The following is an example of an option display, select the shipping service courier service on an online shop site in Fig 4.

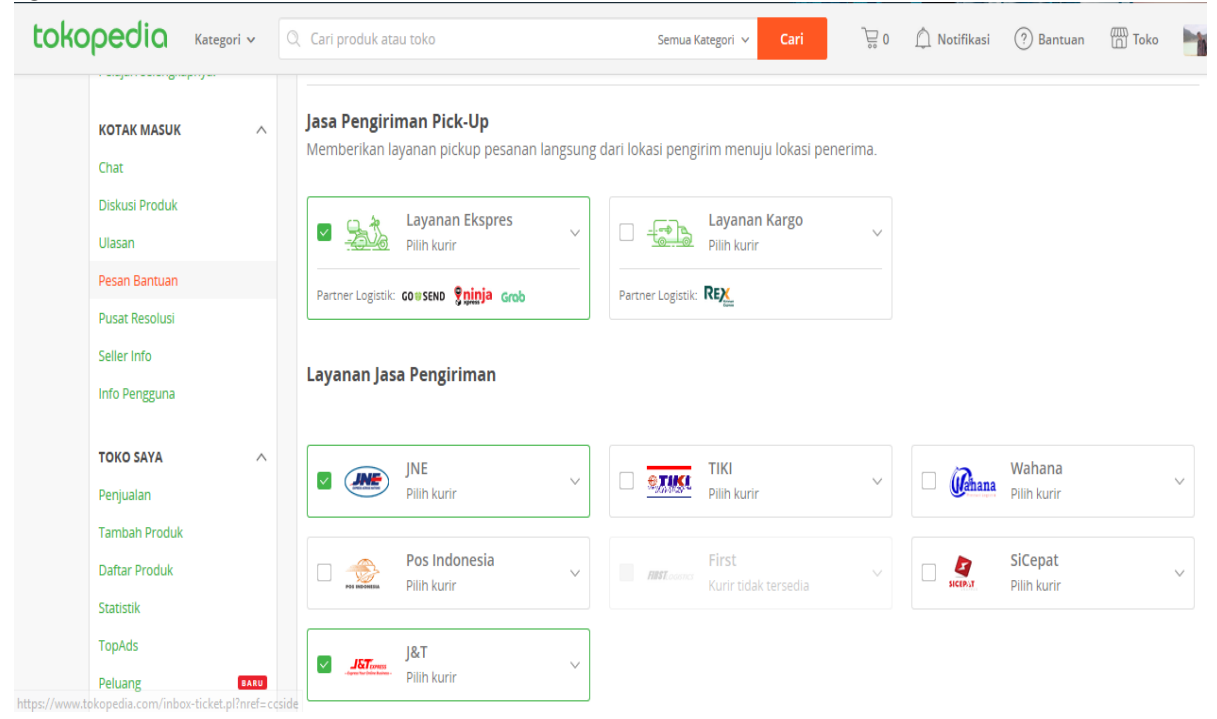

Fig 4. Selection options for courier services provided. The figure was adopted from www.tokopedia.com was taken on Nov 24, 2018.

Apart from the view for traders/sellers in an online shop site. At this stage will discuss the display for buyers who have made a purchase and want to make a payment. On this online shop site, buyers are given the convenience to make transactions such as the availability of a selection service for a distribution method that can be done in various ways and can also choose to use the shipping courier services that the buyers want to deliver the goods they buy. The following is an example of an online shop site that is easy to use by buyers to make e-commerce transactions in Figure 5.

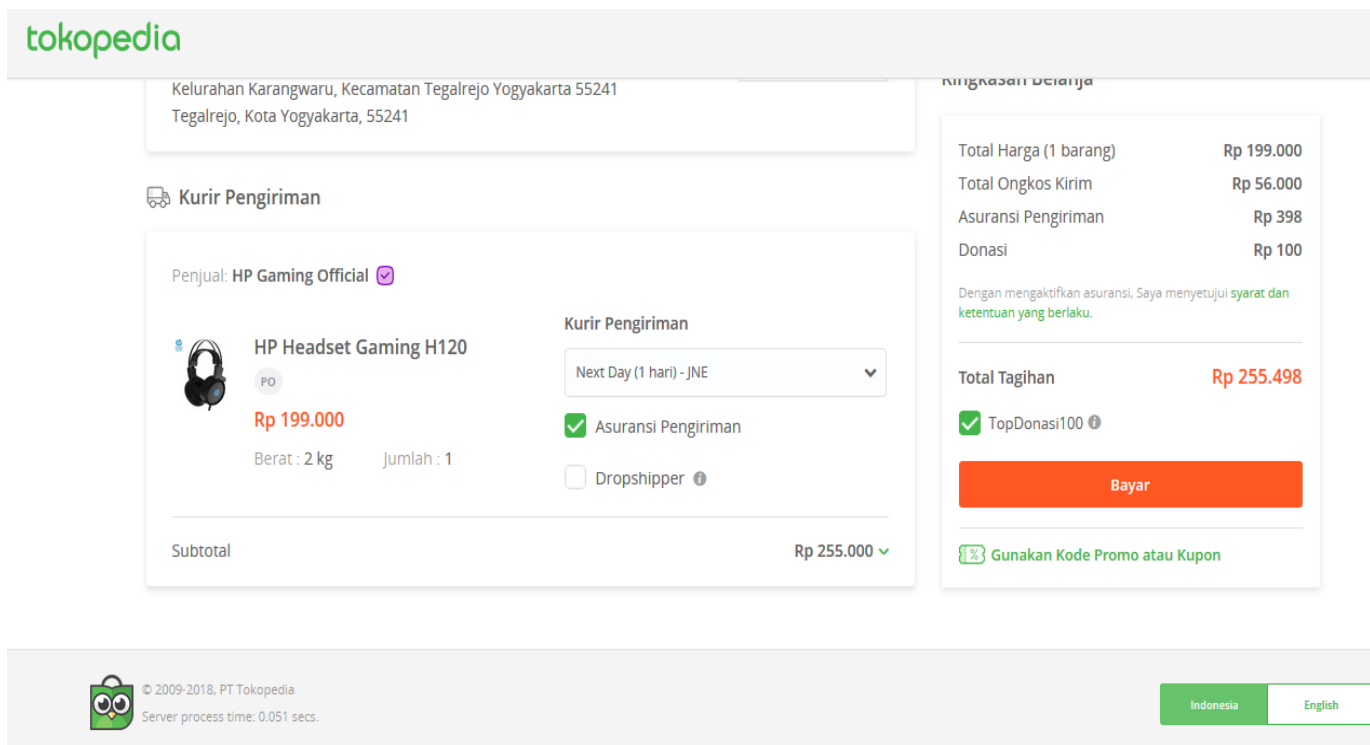

Fig 5. Payment form. The figure was adopted from www.tokopedia.com was taken on Nov 24, 2018.

After all payment processes have been completed, the buyer only waits for the items he buys to be sent to the address according to the buyer wants. If the payment is correct, then the item will be sent to the buyer. And the time of delivery of goods until it reaches the buyer based on the distance and courier service that the buyer wants to use when making a transaction on the online shop, and based on the data and journals, it can be concluded that e-commerce is a transaction activity that is carried out virtually to do online shopping activities that can be done anywhere and anytime by using e-commerce technology and the internet. So that it is possible for anyone and anywhere for do e-commerce activities [8]. 


\section{Conclusion}

The development of technology makes it easy for people. For e-commerce students, it can make a student learn to take advantage of business opportunities easily, and with the existence of e-commerce can help students' lives to earn income without having to interfere with their answers. Because e-commerce using the online shop is very safe to make transactions and do not need to leave home just by using cellulite and internet telephones, all e-commerce transaction activities can be done quickly and efficiently.

\section{References}

[1] Rana D., and Davoud N.: The Impact of E-commerce and R\&D on Economic Development in Some Selected Countries. Procedia - Social and Behavioral Sciences, Tabriz, Iran. $229354-62$ (2016).

[2] Nuray T.: The impact of e-commerce on international trade and employment.Procedia Social and Behavioral Sciences Istanbul, 24 745-53 (2011).

[3] Martin H., Eva K., and Radovan M.: The importance of e-mail marketing in e-commerce. Procedia Engineering, Zilina, Slovakia, 192342 - 47 (2017).

[4] Roberto A., Davide D., and Vito FModeling the rational behavior of Individuals on an ecommerce system. Operations Research Perspectives Alessandria Italy, 522 - 31.: (2018).

[5] Pittawat U.: Adoption E-Commerce for Export Market of Small and Medium Enterprises in Thailand. Procedia - Social and Behavioral Sciences Bangkok, Thailand, $207111-20$ (2015).

[6] Adel. A. A.: E-commerce in Developing Countries and How to Develop Them During the Introduction of Modern Systems. Procedia Computer Science Jeddah, Saudi Arabia, $65479-83$ (2015).

[7] Rita R., and John D.: Determinant Factors of E-commerce Adoption by SMEs in Developing Country: Evidence from Indonesia. Procedia - Social and Behavioral Sciences Huddersfield, United Kingdom, $195142-50$ (2015).

[8] Mesut S., Ahmet I., and Sefer S.: The Potential of E-commerce for SMEs in a Globalizing Business Environment. Procedia - Social and Behavioral Sciences Istanbul,Turkey, 15035 - 45 (2014).

[9] Dewi S.N.: E-Commerce Untuk Pemasaran Produk Usaha Kecil dan Menengah. Jurnal Manajemen \& Bisnis 171 (2011)

[10] Eddy S.S.: Enterpreneurship Menjadi Pebisnis Ulung. Pt. Elex Media Komputindo Kompas Gramedia, Universitas Komputer Indonesia, Indonesia (2014).

[11] Eddy S.S, and Rahmansyah, M. R.: Use of internet as product marketing media using internet marketing method. IOP Conference Series: Materials Science and Engineering IOP Publishing, 4071012053 (2018). 